\title{
Evaluation of Vibrational Properties of a Three-wheeled Vehicle in Terms of Comfort
}

\author{
Jan Dizo, Miroslav Blatnicky \\ Faculty of Mechanical Engineering, University of Zilina. Univerzitna 8215/1, 01026 Zilina. Slovak Republic. E-mail: \\ jan.dizo@fstroj.uniza.sk,miroslav.blatnicky@fstroj.uniza.sk
}

\begin{abstract}
Vibrational properties of road vehicile are ussually evaluated according to two criterions, i. e. in terms of comfort for passengers and in terms of drive safety and roadway load. The topic of this article is focused on evaluation of passenger's ride comfort of a three-wheeled road vehicle. From the ride comfort point of view vertical vibration is decisive. Vertical vibration is given by obtained accelerations in given position on an assessed vehicle when it is driving on a road with various surface qualities within required time intervals. In the vehicle's design phase its vibrational properties are detected and evaluated by means of simulation computations on a virtual model. In our research we have assessed ride comfort of the three-wheeled vehicle, which were designed in our workplace. For purposes of dynamic analyses we have used multibody approach using Simpack software. The objective of this work is verification of the relevance of the current mounted suspension system for the greater driving speeds range of the three-wheeled vehicle and for different road qualities.
\end{abstract}

Keywords: Three-wheeled vehicle, Ride comfort for passenger, Multibody system, Simulation computation

\section{Introduction}

The comfort for passengers is one of the most important aspects, which has to be evaluated for every newly designed vehicle and it is assessed on the basis of standards [16]. Pssengers in transport means are exposed to vibrations and shaking, which can influence, mainly deteriorate, in different ways oganic functions and also cause health troubles. These adverse effects lead to driver's tiredness, which affects his performance and driver-perception abilities. It increases the danger of road accident occurence. For vibration of vehicles total vibration is importnat, i. e. vibrations, transmitted from a seat, which an exposed person sits on, to a whole body.

Acting vibrations cause forced vibrations of some human body's parts or the whole body. Then, physical properties (such as intensity and frequency) and mode of transmition are decisive factors. If the exciter frequency is close to the eigenfrequency of same important apparatus, some part of human body or even the whole human body, it comes to serious resonant effects [26]. In our work we focus on the evaluation of ride properties of a three-wheeled vehicle in terms of ride comfort for passengers.

Since electrification of public transport represents quite effective way for reducing of the environmental burden, an analysed vehicle uses electric power-train [2, 30]. The electric vehicle was developed in our workplace as the results of scientists's and researchers's effort to designed utility urban vehicle with modern, very effective and environmental accteptable power-train, which does not produce any exhaust gases during its operation. During designing of the vehicle there was necessary take into account maintenance and repairs costs $[5,6,13]$.

Analyses of ride comfort were carried out on the computational model of a vehicle.

\section{MBS model of a vehicle}

The examined vehicle composes of several construction units. Some from them, such as suspension system, rear axle, powertrain are adopted from the comercial produced tricycle were not developed completely new, but they were adopted from existing three-wheeled vehicle, which is produced commercially. But, the frame of the vehicle and the steering system are designed completely newly so that they meet requirements for modern and effective transport mean.

For evalaluation of passenger's comfort level of a vehicle Simpack software was used. This simulation software represents on of the most widely used MBS software, which serves for many researchers and engineers as a tool for creating MBS models of differend kind of transport means, such a road vehicle, rail vehicle etc. [3, 9, 14, 29].

In terms of mechanics, the vehicle model represents a complex mechanical system includes several different elements, such as rigid bodies (vehicle body - frame, parts of steering system and others), force elements (suspension - springs, dampers) and special elements (wheels). In addition there is necessary to define excitation of mechanical system (vehicle model). When we discuss about passenger's ride comfort, we consider mainly vibrations of vehicle, which are caused by road surface irregularities. Generally, road irregularities represent undesirable effects, which come to a human body through tyres, a suspension system, a seat cushion etc. Then, they influence vibration properties of a vehicle mechanical system [12, $18,20,25]$.

As we know, the multibody model of a threewheeled vehicle is from the mathematical point of view system of second order differential equations called equations of motion. Their standard matrix form is:

$$
\boldsymbol{M} \cdot \ddot{\boldsymbol{q}}+\boldsymbol{B} \cdot \dot{\boldsymbol{q}}+\boldsymbol{C} \cdot \boldsymbol{q}=\boldsymbol{Q}_{i},
$$

where $\boldsymbol{M}$ is the mass matrix,

$\boldsymbol{B}$ is the damping matrix

$C$ is the stiffness matrix,

$\boldsymbol{q}$ is the vector of generalized coordinates and

$\dot{\boldsymbol{q}}, \ddot{\boldsymbol{q}}$ are time derivations of the $\boldsymbol{q}$ vector, i. e. velocities and accelerations, respectively. 
Virtual multibody model of the analysed tricycle created in Simpack software is shown in Fig. 1.

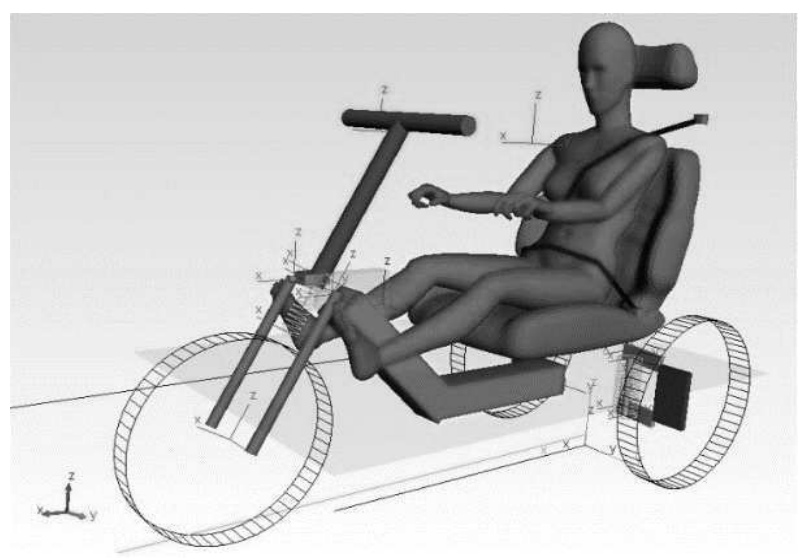

Fig. 1 Virtual model of an analysed three-wheeled vehicle

As it was mentioned above, the basis of the powertrain system and individual elements of the suspension system is adopted from the original tricycle, which is produced and sold commercially. Therefore, in the current state, the suspension system of the tricycle consists of elements with linear characteristics. The front suspension includes a coil spring and a fork. The front wheel suspension system does not use any damper. Other parts of the front wheel suspension are completely newly designed and constitute the innovative steering system ensuring better overturning stability.

The rear axle uses independent suspension of wheels. It is constructed by means of two swinging arms, on which the wheel hub is mounted. On each side coil springs and hydraulic dampers are installed.

\section{Vehicle and road interface}

Generally, for the setting up an entire vehicle model several steps is necessary to perform. As is was mentioned above, the complex multibody system represents the interface of a vehicle and a road. For this purposes particular modelling elements serve. They are defined in the contact of a wheel and road.

Since the Simpack software is a universal MBS software intended for modelling road as well as rail vehicles, in the database several contact models are available. Various contact models provide information about calculated quantities, which are distributed in a contact patch $[21,28]$. Despite the fact that the problem of the contact of a wheel on a road or rail seems to be similar, many different models are developed $[22,23,31]$ regarding to calculation of the contact problem. Especially calcuation of normal and tangential stress in contact patch for wheel/rail contact, calculation of dynamic effects and some other important physical quantities $[7,10,11,24]$ is quite different in comparison to wheel/road contact models.

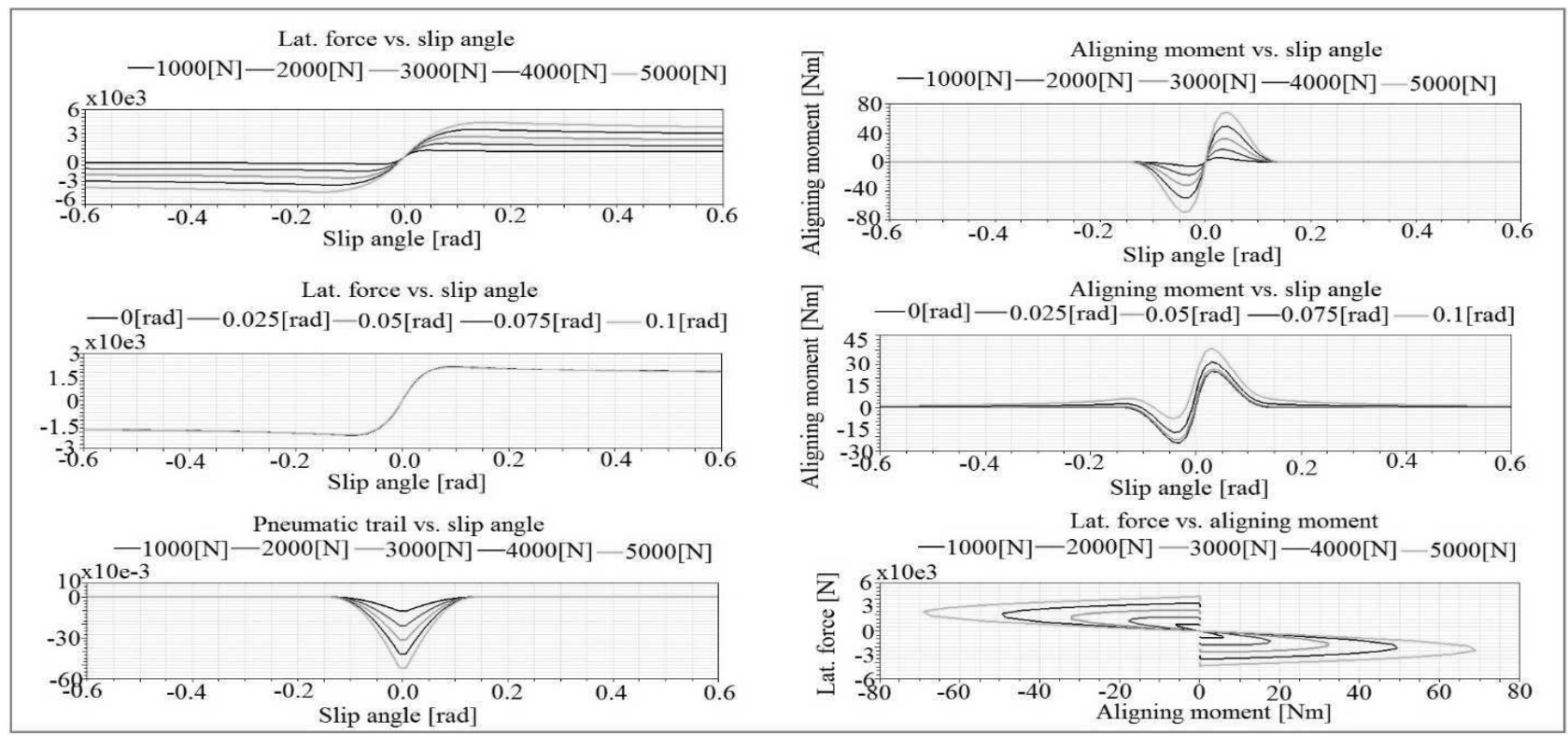

Fig. 2 Image of the lateral characteristics of used tyre model

The used computational software provides several tyre models for road vehicles from the simplest to the most complex models. These modelling elements represents direct interface between a vehicle model and a road model. In our research we have used Pacejka Similarity model, which is often and widely used for standard problems about road vehicles dynamics. This approach is in the used software supposed as multi-force element and allows to apply a number of different forces and torques to specified elements (bodies). Using this complex force element we obtain many output values, e. g. rotational velocity, longitudinal velocity, elastic vertical force, viscous vertical force, effective rolling radius, slips in all directions, rolling resistance torque etc. Figure 2 shows the lateral characteristics of the used tyre model.

As in the reality, the road model requires including the road irregularities, which simulate excitation of vehicle mechanical system. We have input stochastic irregularities into a road model in the form of power spectral density (PSD). This functionality allows creating a pseudo 
stochastic road excitation signal in distance domain in the basis of PSD function.

From the terms of statistics a roadway is considered as a random signal. The particular roadway type we can interpreted by means of the integrated white noise, which intensity equals to the PSD of the considered roadway. Individual types of roadways can be characterised by functions with corresponding parameters. In the principle, the PSD is a tool for classification of a roadway.
The PSD of a roadway is determined by experiments. In standard [17] various types of roadways are classified according to their characteristics into several categories. The PSD is in logarithmic scale approximated by a linear function. Figure 3 shows example waveforms of PSDs of various roadways types considering a frequency of the signal, where roadway quality " $A$ " represents the very good cement concrete and roadway quality " $\mathrm{E}$ " characterised the bad pavement.

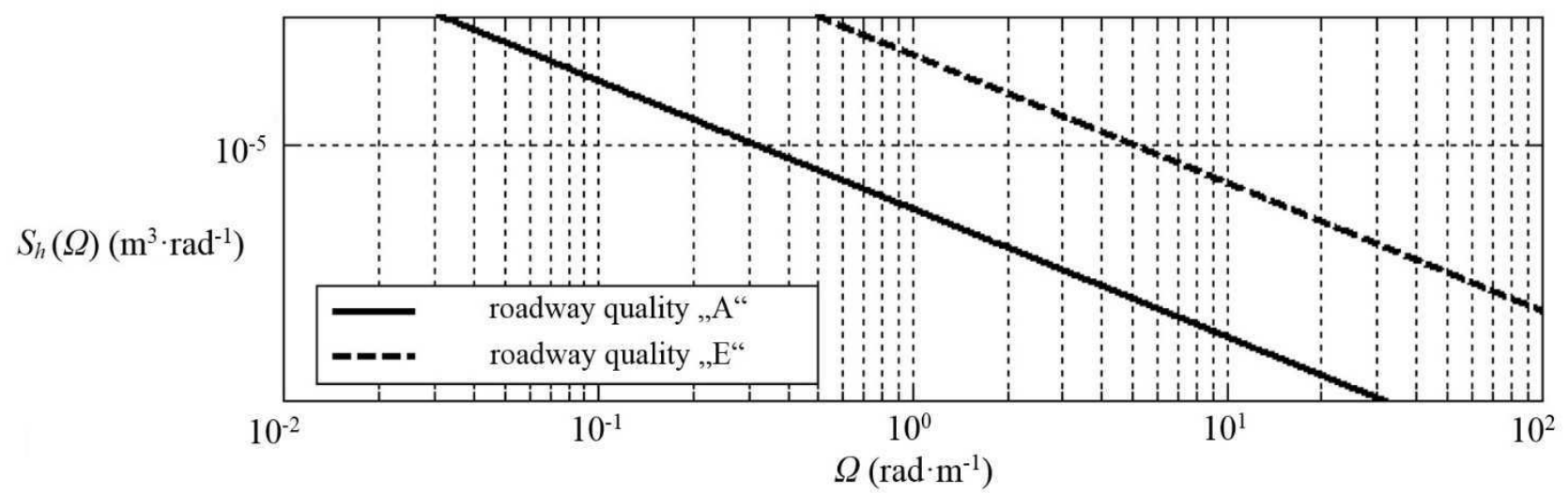

Fig. 3 Example of waveforms of the PSD for various roadsurface qualities.

For the statistic description of the PSD there is most often used following formulation:

$$
S_{h}(\Omega)=S_{h}\left(\Omega_{0}\right) \cdot\left(\frac{\Omega}{\Omega_{0}}\right)^{-n}\left[\mathrm{~m}^{3} \cdot \operatorname{rad}^{-1}\right],
$$

where $\Omega\left[\mathrm{rad} \cdot \mathrm{m}^{-1}\right]$ is the current found angular frequency, $\Omega_{0}\left[\mathrm{rad} \cdot \mathrm{m}^{-1}\right]$ is the reference track angular frequency,

$n[-]$ is the roadway undulation parameter and

$S_{h}\left(\Omega_{0}\right)\left[\mathrm{m}^{3} \cdot \mathrm{rad}^{-1}\right]$ is the value of PSD in the reference point.

The mentioned standard characterises several qualities of roadways from the vertical irregularities point of view.

In Simpack modelling library we can find defined PSD of various roadway qualities. We have chosen seven types of predefined PSD in distance domain, which we have marked as following:

- A - very good cement concrete,

- B - good cement concrete,

- C - good asphalt concrete,

- D - good macadam,

- E - medium asphalt concrete,

- F - medium pavement,

- $\mathrm{G}$ - bad pavement.

\section{Numerical analyses and results}

Analyses of the tricycle were conducted on a straight road model including surface irregularities in accordance with the section 3 .

We have interested to evaluate dynamic properties of the tricycle in terms of passenger comfort under different operational conditions. The installed original power-train allows to drive at the speed of $15 \mathrm{~km} \cdot \mathrm{h}^{-1}$, but by modification of the control unit we can increase the maximum speed up to $30 \mathrm{~km} \cdot \mathrm{h}^{-1}$. As the main use of the threewheeled vehicle is considered in the urban transport, we have chosen the range of tested speed from $10 \mathrm{~km} \cdot \mathrm{h}^{-1}$ to $30 \mathrm{~km} \cdot \mathrm{h}^{-1}$. All analyses were recoreded at such a sampling rate, which corresponds to the set speed of driving. Simulations were performed for vehicle driving on seven roadways from very good cement concrete to bad pavement, which qualities were defined using the PSD in compliance with the section 3 .

At present, the analysed three-wheeled vehicle, which is the object of our research, is designed as a single-seat vehicle. According to the standard, for evaluation of the passenger ride comfort there is necessary to found out values of accelerations at proper position. In this case, the seat of a driver is such a position.

Defined simulation conditions results to large number of simulations of tricycle driving. As the basic outputs from simulation computations are accelerations on the driver seat in unprocessed form. As the example of the accelerations outputs, waveforms of such signals are shown in Fig. 4. It contains several accelerations outputs depending on different driving speed of the vehicle (arranged in columns), i. e. $10 \mathrm{~km} \cdot \mathrm{h}^{-1}, 20 \mathrm{~km} \cdot \mathrm{h}^{-1}$ and $30 \mathrm{~km} \cdot \mathrm{h}^{-1}$ as well as depending on different roadway surface qualities (arranged in lines), namely for very good cement concrete, good cement concrete and bad pavement. Results are displayed in time domain. From this figure we can see, that the worse quality of a road causes significant accelerations on the driver seat and thus also vibrations. We can see, as we would assume, that values of accelerations increase proportionally with the greater driving speed and with worsening roadway quality. 


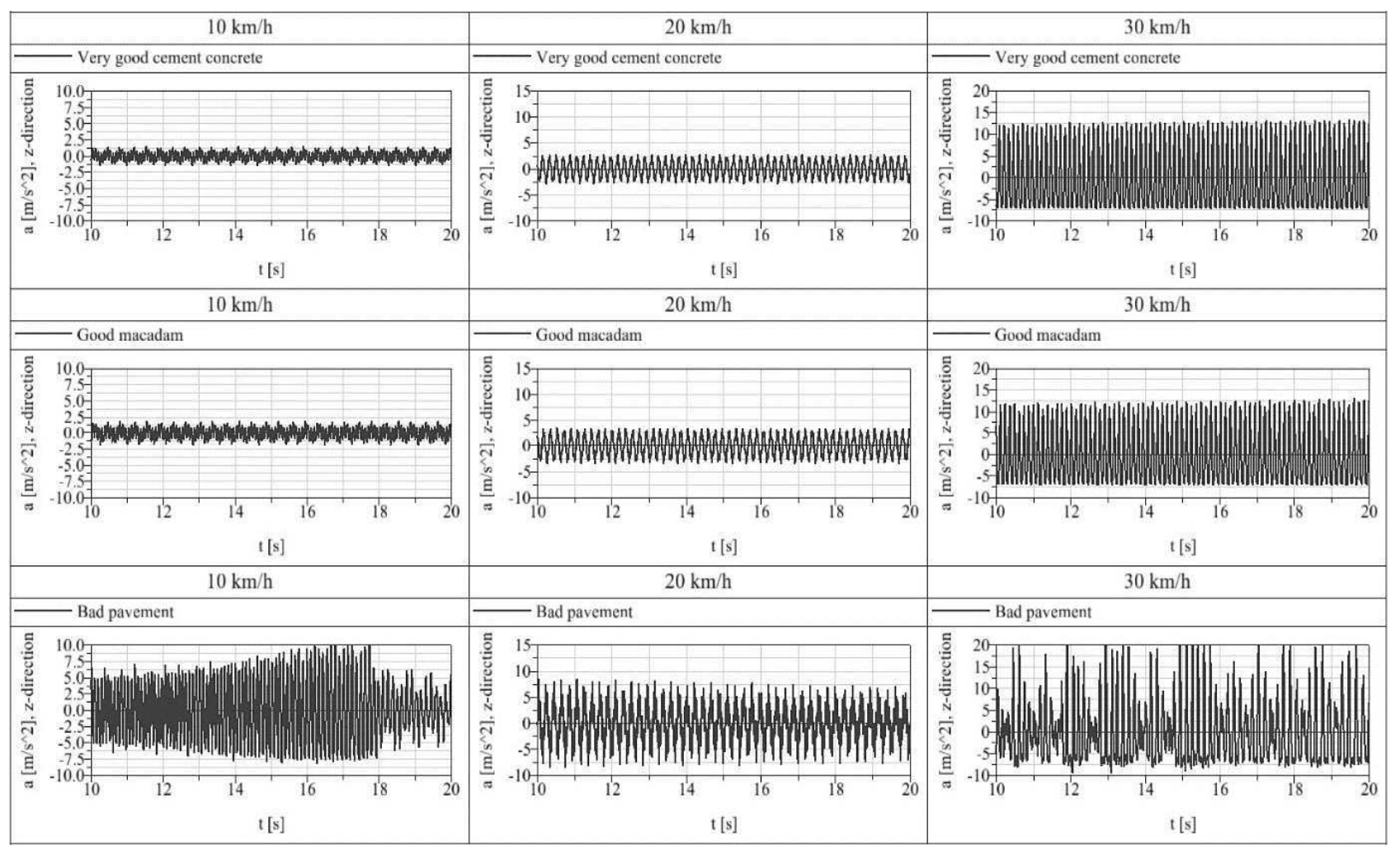

Fig. 4 Waveforms of unprocessed accelerations signals on the driver seat for various driving conditions.

With vibration the ride comfort for passenger is very close related. In the case of the tricycle driving on the road of best quality and at the lowest speed we can see, that also accelerations are smallest. If the road quality is worse, but the speed is the same, values of accelerations for speed of $10 \mathrm{~km} \cdot \mathrm{h}^{-1}$ and $20 \mathrm{~km} \cdot \mathrm{h}^{-1}$ do not arise such significantly expect of driving at the speed of $30 \mathrm{~km} \cdot \mathrm{h}^{-1}$, when the accelerations arise much significantly.

The similar situation we can observe, when we assess waveform of accelerations depending on roadway quality. Thus, with the worse road quality and greater speed also accelerations are increasing. When the vehicle drive at the greatest analysed speed and on the worst quality road, vibrations measured on the driver seat are also greatest.

In the field of road vehicles, we can consider vertical oscillation as the ultimate criterion. Eigenfrequencies of the human body are for this direction of oscillation in the range of $4-6 \mathrm{~Hz}$. In this frequency range the top part of a human body is resonance excited as well as vertebras and a stomach. For the horizontal direction of total vibrations the resonance oscillation occur about 1 - $3 \mathrm{~Hz}$. Evaluation of dynamic effects of vibration demands processing of acceleration signals. Depending on used methods, one can apply a chosen process for calculation of resulting accelerations effects on a human body or also on a vehicle structure $[1,4]$

The effect of oscillation on the human body is usually evaluated according to the effective values of accelerations $a_{e f}$, which is defined as:

$$
a_{e f}=\sqrt{\lim _{T \rightarrow \infty} \frac{1}{T} \cdot \int_{0}^{T} a^{2}(t) \cdot d t}\left[\mathrm{~m} \cdot \mathrm{s}^{-2}\right],
$$

where $T[\mathrm{~s}]$ is the maximum value of time interval and $a\left[\mathrm{~m} \cdot \mathrm{s}^{-2}\right]$ is the value of acceleration.

For the estimation of human body reaction on mechanical oscillation the intensity of the oscillation, frequency, direction and time of oscillation is important.

The evaluation of the road vehicles oscillation effect is performed in accordance with the ISO 2631 standard. This standard determines limits of effective accelerations values depend on the time and frequency of oscillation for vertical and horizontal direction of oscillations. In the standard there are defined so called the reduced performance limit, which are the criterion of road vehicles oscillation and further the reduced comfort limit and health hazard limit. The comparative diagram for the process of ride comfort evaluation is shown in Fig. 5. In this graph several curves charatrising sensitivity of a human body to vertical veibration (i. e. vertical accelerations) are plotted. In the lower right part of the graph introduces, how to use this graph.

We have performed several simulations for various quality of road and also for various driving speeds. In order to estimate the limit of the right comfort propertly, we have used a particular functionality of the used software available in postprocessor. Results of simulation computations of the three-wheeled vehicle driving on various road surfaces quality and their effects on human body sensitivity due to vertical oscillations are listed in Tables 1 to 6.

There are displayed results gradually for $10 \mathrm{~km} \cdot \mathrm{h}^{-1}$, $15 \mathrm{~km} \cdot \mathrm{h}^{-1}, 20 \mathrm{~km} \cdot \mathrm{h}^{-1}, 25 \mathrm{~km} \cdot \mathrm{h}^{-1}$ and $30 \mathrm{~km} \cdot \mathrm{h}^{-1}$ and for seven road quality. From these tables we can identified, that increased driving speed as well as worse quality of a road has negative effect on the passenger ride comfort. 
Sensitivity of a human body to vertical vibration


Fig. 5 Various human sensitivities depending on vertical vibrations

Tab. 1 Evaluation of vertical oscillation influence on a human body for driving speed of $10 \mathrm{~km} \cdot \mathrm{h}^{-1}$

\begin{tabular}{|c|c|c|c|c|c|c|c|}
\hline \multicolumn{8}{|c|}{$\mathbf{1 0} \mathbf{~ k m} \cdot \mathbf{h}^{-1}$} \\
\hline Road quality & A & B & C & D & E & F & G \\
\hline $\begin{array}{c}\text { Effective acceleration value } \\
\boldsymbol{a}_{e f}\left[\mathbf{m} \cdot \mathbf{s}^{-2} \text { ] }\right.\end{array}$ & 0.75 & 1.12 & 0.92 & 0.98 & 2.31 & 3.33 & 3.88 \\
\hline $\begin{array}{c}\text { Limit of oscillation influence } \\
\boldsymbol{t}[\mathrm{min}]\end{array}$ & 150 & 105 & 138 & 108 & 22 & 8 & 1.2 \\
\hline
\end{tabular}

Tab. 2 Evaluation of vertical oscillation influence on a human body for driving speed of $15 \mathrm{~km} \cdot \mathrm{h}^{-1}$

\begin{tabular}{|c|c|c|c|c|c|c|c|}
\hline \multicolumn{8}{|c|}{$\mathbf{1 5} \mathbf{~ k m} \cdot \mathbf{h}^{-1}$} \\
\hline Road quality & A & B & C & D & E & F & G \\
\hline $\begin{array}{c}\text { Effective acceleration value } \\
\boldsymbol{a}_{e f}\left[\mathbf{m} \cdot \mathbf{s}^{-2}\right]\end{array}$ & 0.93 & 1.12 & 1.02 & 1.14 & 1.78 & 2.45 & 3.88 \\
\hline $\begin{array}{c}\text { Limit of oscillation influence } \\
\boldsymbol{t}[\mathrm{min}]\end{array}$ & 135 & 105 & 100 & 102 & 75 & 25 & 1.2 \\
\hline
\end{tabular}

Tab. 3 Evaluation of vertical oscillation influence on a human body for driving speed of $20 \mathrm{~km} \cdot \mathrm{h}^{-1}$

\begin{tabular}{|c|c|c|c|c|c|c|c|}
\hline \multicolumn{8}{|c|}{$20 \mathrm{~km} \cdot \mathrm{h}^{-1}$} \\
\hline Road quality & $\mathbf{A}$ & B & $\mathrm{C}$ & D & $\mathbf{E}$ & $\mathbf{F}$ & $\mathbf{G}$ \\
\hline $\begin{array}{c}\text { Effective acceleration value } \\
a_{e f}\left[\mathrm{~m} \cdot \mathrm{s}^{-2}\right]\end{array}$ & 1.55 & 1.67 & 1.65 & 1.86 & 2.62 & 3.08 & 3.40 \\
\hline $\begin{array}{l}\text { Limit of oscillation influence } \\
t[\text { min] }\end{array}$ & 90 & 83 & 87 & 54 & 14 & 8 & 5 \\
\hline
\end{tabular}

Tab. 4 Evaluation of vertical oscillation influence on a human body for driving speed of $25 \mathrm{~km} \cdot \mathrm{h}^{-1}$

\begin{tabular}{|c|c|c|c|c|c|c|c|}
\hline \multicolumn{8}{|c|}{$25 \mathrm{~km} \cdot \mathrm{h}^{-1}$} \\
\hline Road quality & $\mathbf{A}$ & B & $\mathrm{C}$ & D & $\mathbf{E}$ & $\mathbf{F}$ & $\mathbf{G}$ \\
\hline $\begin{array}{c}\text { Effective acceleration value } \\
a_{e f}\left[\mathrm{~m} \cdot \mathrm{s}^{-2}\right]\end{array}$ & 2.87 & 2.94 & 2.99 & 3.33 & 4.55 & 4.65 & 4.74 \\
\hline $\begin{array}{c}\text { Limit of oscillation influence } \\
t[\text { min] }\end{array}$ & 12 & 10.5 & 9 & 8 & 0.92 & 0.82 & 0.75 \\
\hline
\end{tabular}

Tab. 5 Evaluation of vertical oscillation influence on a human body for driving speed of $30 \mathrm{~km} \cdot \mathrm{h}^{-1}$

\begin{tabular}{|c|c|c|c|c|c|c|c|}
\hline \multicolumn{8}{|c|}{$30 \mathrm{~km} \cdot \mathrm{h}^{-1}$} \\
\hline Road quality & $\mathbf{A}$ & B & $\mathrm{C}$ & D & $\mathbf{E}$ & $\mathbf{F}$ & $\mathbf{G}$ \\
\hline $\begin{array}{c}\text { Effective acceleration value } \\
a_{e f}\left[\mathbf{m} \cdot \mathbf{s}^{-2}\right]\end{array}$ & 6.68 & 6.61 & 6.65 & 6.50 & 5.88 & 5.64 & 5.42 \\
\hline $\begin{array}{l}\text { Limit of oscillation influence } \\
t \quad t \text { min] }\end{array}$ & 0.15 & 0.18 & 0.17 & 0.20 & 0.45 & 0.35 & 0.30 \\
\hline
\end{tabular}

Using the Simpack simulation package we have found out, that our simplified model of the analysed vehicle has seven eigenfrequencies, which there is necessary to take into account for the passenger ride comfort evaluation. For the vertical direction of the oscillation, we take the eigenfrequency of $3.8 \mathrm{~Hz}$ for assessment of the passenger ride comfort. Then, we can found out, how long the passenger of the vehicle could drive it. We have focused on evaluation it from the reduced performance limit point of view. 
Compare now values of effective accelerations for different road quality and different driving speed with the graph in Fig. 5. We can identify, that the driving of the vehicle on the road with "A“ quality at the speed of $10 \mathrm{~km} \cdot \mathrm{h}^{-1}$ and $15 \mathrm{~km} \cdot \mathrm{h}^{-1}$ is comfortable. It corresponds with the designed maximal driving speed. But, if we investigate comfort for greater speed, we can see, that driving on the good quality road is much less comfortable with increasing driving speed. And also, driving of the vehicle on the worse road quality, mainly on the " $F$ " and " $G$ " is very uncomfortable, even dangerous for human health. It shows important finding. The modification of the power-train of the analysed vehicle is the future intention of its designers. The main addition of such changes in power-train consist in increasing the driving speed of the three-wheeled vehicle up to supposed speed of $30 \mathrm{~km} \cdot \mathrm{h}^{-1}$, or more eventually. Since there is the assumption of reaching longer endurance distance as well, a driver will spend more time in the vehicle.

As it was proven, the suspension system currently used in the vehicle does not conform to comfort criterion, mainly on roadways with bad quality surfaces. Nay, simulation analyses have shown, that current suspension system is dangerous in terms of ride comfort for passengers. Therefore, from the ride comfort the optimisation of the suspension parameters is necessary to perform. Further research in this field will be focused also on application of advanced functionalities of computational softwares, which means the flexible model of a frame will be applied into the MBS model of the tricycle. One can expect, that the considering the flexibility of a frame can cause greater damping of vibration and after all the level of passenger comfort can be more favourable in comparison to results with a rigid frame. But, such a flexible multibody model requires preparation of a frame model in a finite element software [8, 19, 29, 32], such as, for example Ansys. However, this approach increases time for preparation of a model, increases the computational time and raises requirements of used computational software as well.

Since the designed three-wheeled vehicle is considered as a vehicle, which could be eventually used for common urban operation. Therefore, in addition to just described technical changes modification of the current design of a frame [15] will be necessary to perform in such a way to meet requirements on one hand with regard to passengers' protection against weather conditions (direct sunlight, wind, rain, etc.) and on other hand regarding the improvement its aerodynamic properties [27].

\section{Conclusion}

Through the survey and evaluation method in ISO 2631 international standard, considering the influence of the different road qualities as well as driving speeds, we may reflect comprehensive and accurately how comfortable the passenger feels riding our threewheeled vehicle. The evaluation of passenger ride comfort of the designed three-wheeled vehicle was performed. Comfort was assessed driving of the vehicle on various roadway surfaces and at various speeds as well. Based on performed computations one can say, what time margin is acceptable for a passenger driving in the analysed vehicle on same or other roadsurfaces as well as at same or other speed. There was found out, that current parameters of the used suspension system do not meet strict comfort criterion, therefore further optimisation of the suspension system will be necessary.

\section{Acknowledgement}

This work was supported by the Cultural and Educational Grant Agency of the Ministry of Education of the Slovak Republic within the project No. KEGA 007ŽU4/2017: Modernization of the Vehicles and engines study program.

\section{References}

[1] BITTNER, V., TUCEK, R., PANSKA, S., SVOBODA, M., JELEN, K. (2017). Using the fourier transform in the analysis of vibration load tests of heterogeneous mechanical systems. In: Manufacturing Technology, Vol. 17, No. 6, pp. $836-841$.

[2] BUREIKA, G., STEISUNAS, S. (2016). Complex evaluation of electric rail transport implementation in Vilnius city. In: Transport Problems, Vol. 11, No. 1, pp. $49-60$.

[3] CHALUPA, M., VEVERKA, J. (2016). Handling simulation of vehicles. In: Manufacturing Technology, Vol. 16, No. 6, pp. 1269 - 1274.

[4] CHUDZIKIEWICZ, A., MELNIK, R. (2012). Statistical analysis of vibration for the rail vehicle suspension monitoring system. In: Proceedings of the $13^{\text {th }}$ Mini Conference on Vehicle System Dynamisc, Identification and Anomalies, VSDIA 2012, pp. 149 - 155. Budapest, Hungary.

[5] DROZDZIEL, P., KOMSTA, H., KRZYWONOS, L. (2012). An analysis of costs of vehicle repairs in a transportation company. Part I. In: Transport Problems, Vol. 7, No. 4, pp. $67-75$.

[6] DROZDZIEL, P., KOMSTA, H., KRZYWONOS, L. (2012). An analysis of costs of vehicle repairs in a transportation company. Part II. In: Transport Problems, Vol. 7, No. 4, pp. 5 11.

[7] GERLICI, J., GORBUNOV, M., KRAVCHENKO, K., DOMIN, R., KOVTANETS, M., LACK, T. (2017). Slipping and Skidding occurance probability decreasing my means of the friction controlling in the Wheel/Braking Pad and wheel-rail contacs. In: Manufacturing Technology, Vol. 17, No. 2, pp. $179-186$.

[8] GERLICI, J., GORBUNOV, M., KRAVCHENKO, K., PROSVIROVA, O., LACK, T., HAUSER, V. (2018). Assessement of innovative methods of the rolling stock brake system efficiency increasing. In: Manufacturing Technology, Vol. 18, No. 1, pp. 35 - 38.

[9] GERLICI, J., GORBUNOV, M., NOZHENKO, O., PISTEK, V., KARA, S., LACK, T., 
KTAVCHENKO, K. (2017). About creation of bogie the freight car. In: Communications - Scientific Letters of the University of Zilina, Vol. 19, No. 2, pp. $29-35$.

[10] GERLICI, J., LACK, T. (2003). Rail geometry analysis (from the point of view of wearing in the operation). In: Komunikacie, Vol. 5, No. 1, pp. 43 $-51$.

[11] GERLICI, J., LACK, T., KADOROVA, M. (2004). Calculation of the equivalent conicity function of the railway wheelset tread profile at the delta $\mathrm{R}$ function with a negative slope. In: $\mathrm{Ko}$ munikacie, Vol. 6, No. 2, pp. 49 - 56.

[12] GERLICI, J., SAKHNO, V., YEFYMENKO, A., VERBITSKII, V., KRAVCHENKO, A., KRAVCHENKO, K. (2017). The stability analysis of two-wheeled vehicle model. In: MATEC Web of Conferences, Vol. 157.

[13] GRENCIK, J., POPROCKY, R., GALLIKOVA, J., VOLNA, P. (2018). Use of risk assessment methods in maintenance for more reliable rolling stock operation. In: MATEC Web of Conferences, Vol. 157.

[14] HAUSER, V., NOZHENKO, O. S., KRAVCHENKO, K. O., LOULOVA, M., GERLICI, J., LACK, T. (2017). Proposal of a mechanism for setting bogie wheelsets to radial position while riding along track curve. In: Manufacturing Technology, Vol. 17, No. 2, pp. $186-192$.

[15] HARUSINEC, J., SUCHANEK, A., LOULOVA, M., KURCIK, P. (2019). Design of a prototype frame of an electrically driven three-wheel vehicle. In: MATEC Web of Conferences, to be published.

[16] ISO 2631:1997. Mechanical vibration and shock. Evaluation of human exposure to whole-body vibration. Part I: general Requirements. International Organization for Standardization.

[17] ISO 8608:2000. Mechanical vibration. Road surface profiles. Reporting of measured data.

[18] ISTENIK, R., BARTA, D., MUCHA, W. (2004). Influence of the wheels on the automobile dynamics. In: Komunikacie, Vol. 6, No. 1, pp. 26-28.

[19] KLIMENDA, F., RYCHLIKOVA, L., HUSAR, S., SOUKUP, J. (2017). Dissemination of waves in thin plates. In: Manufacturing Technology, Vol. 17, No. 6, pp. $863-869$.

[20] KOSTRZEWSKI, M. (2017). Analysis of selected vibroacoustic signals recorded on EMU vehicle running on chosen routes under supervised operating conditions. In: Vibroengineering Procedia, Vol. 13, pp. $153-158$.

[21] LACK, T., GERLICI, J. (2005). Contact area and normal stress determination on railway wheel/rail contact. In: Komunikacie, Vol. 7, No. 2, pp. 38 45.

[22] LACK, T., GERLICI, J. (2012). Modified strip method utilisation for wheel/rail contact stress evaluation. In: Proceedings of the $9^{\text {th }}$ International Conference on Contact Mechanics and Wear of Rail/Wheel Systems, CM 2012, pp. 87 - 89.

[23] LACK, T., GERLICI, J. (2009). Railway wheel and rail roughness analysis. In: Komunikacie, Vol. 11, No. 2, pp. $41-48$.

[24] LACK, T., GERLICI, J. (2016). Tangential stresses for non-eliptical contact patches computed by means of a modified FASTSIM method. In: CivilComp Proceedings, Vol. 110.

[25] LOULOVA, M., SUCHANEK, A., HARUSINEC, J. (2017). Evaluation of the parameters affecting passenger riding comfort of a rail vehicle. In: Manufacturing Technology, Vol. 17, No. 2, pp. $224-231$.

[26] LOZIA, Z., KARDAS-CINAL, E. (2016). The use of a linear half-vehicle model for the optimization of damping in the passive suspension system of a railway car. In: Archive of Transport, Vol. 39, No. 3 , pp. $31-49$.

[27] RIEVAJ, V., STOPKA, O., VRABEL, J., MOKRICKOVA, L., SCHMIDT, C. (2016). The impact of air resistance on the fuel consumption in real conditions within the transport opration. In: Communications - Scientific Letters of the University of Zilina, Vol. 18, No. 2, pp. $57-61$.

[28] SAKHNO, V., POLIAKOV, V., TIMKOV, O., KRAVCHENKO, O. (2016). Lorry convoy stability taking into account the skew of semitrailer axes. In: Transport Problems, Vol. 11, No. 3, pp. $69-76$.

[29] SKOCILASOVA, B., SKOCILAS, J. (2015). Solidification of the aluminium alloy in the mold. In: Manufacturing Technology, Vol. 15, No. 5, pp. $909-914$.

[30] SKRUCANY, T., KENDRA, M., SARKAN, B., GNAP., J. (2015). Software simulation of an energy consumption and GHG production in transport. In: Communications - Scientific Letters of the University of Zilina, Vol. 531, pp. $151-160$.

[31] SMETANKA, L., STASTNIAK, P. (2017). Analysis of contact stresses of theoretical and worn profile by using computer simulation. In: Manufacturing Technology, Vol. 17, No. 4, pp. $580-$ 585.

[32] SUCHANEK, A., HARUSINEC, J. (2015). The downhill braked railway wheel structural analysis by means of the ANSYS multiphysics program system package. In: Manufacturing Technology, Vol. 15, No. 1, pp. $945-950$. 